\title{
CORRESPONDENCE
}

To the Editors of The British Journal of Ophthalmology.

DEAR SIRS,-I am disposing of the professional effects of the late Mr. Malcolm Hepburn and have for sale the Transactions of the Ophthalmological Society of the United Kingdom, Vols. 25 to 60 inclusive.

I would be very much obliged if you would bring this to the notice of your readers by publishing this letter.

It might be pertinent to mention as a guide that individual volumes are purchasable from the publishers at a price of $40 \%$ - a Vol., but that Vols. 41, 43, 46; 50, 54 and 55 all of which are contained in this collection are out of print and unobtainable and therefore their value is presumably considerable.

I have the honour to be, Sirs,

Your obedient Servant,

Frank W. LaW.

36, Devonshire Place, W.1

October 1, 1942

\section{CASES OF ORTHOPTIC INTEREST}

To the Editors of THE BRITISH Journal of OPHTHALMOLOGY.

DEAR SIRS, - In view of the fact that I have been responsible in major part for the clinical report of "Two Ċases of Orthoptic Interest," which appeared in the Brit. Jl. of Ophthal. of July, 1942, I take this opportunity of replying personally to the letter from Mr. T. Keith Lyle, which is printed in your issue of September, 1942.

However, despite the manner of Mr. Lyle's reply, I do not intend to be led astray from the purpose of our original communication, which was simply to make a complete statement of collected facts, because I felt that something of nature's truths could be learned by allowing the whole of the facts recorded to speak for themselves.

The scientific enquirer will surely not be irritated when such facts and truths run counter to his pre-conceived ideas.

In the first case recorded, Mr. Lyle agrees that orthoptic treatment would be really unnecessary for the normal development of binocular reflexes, if the eyes are straight when glasses are wornprovided the glasses are worn habitually. In fact, he quotes the 
aptness of the statement of Chavasse "leave 'em alone and they'll come home." In spite of this, Mr. Lyle proceeds to state dogmatically that even in these cases orthoptic treatment is "of great value in helping to stabilise binocular reflexes, and in teaching the patient 'control' so that deviation' of the visual axes does not take place, even periodically, or on such occasions when the glasses are not worn."

I should like to remind Mr. Lyle that no good proofs yet exist to justify these axiomatic dogmas. Further, if the patient or his parents are given the impression that glasses may be discarded before natural cure has occurred, merely because of exercises, grave harm may result.

Perhaps it would be more consistent on Mr. Lyle's part to follow Chavasse completely, and really "leave 'em alone." However, let us apply the preceding statements to the case reviewed.

At the date of discharge, after 2 years 9 months continuous orthoptic treatment, the patient still had a small degree of squint present both with and without glasses. In spite of being taught "control," his mother noticed after his discharge that when he removed his spectacles in the evenings, preparatory to going to bed, his left eye would turn in considerably. Surely this confirms the opinion of our orthoptic department that the result was not a good functional one, but merely cosmetic:

There is no need to emphasise that the utility of occlusion is not a. discovery of modern orthoptic technique. The point is that accommodative squints, par excellence, have been claimed for the happy hunting grounds of orthoptic enthusiasts, whether these cases are straight with glasses or not. Further, we well know that few orthoptists would agree that any particular case could safely be left without his or her ministrations. I present such a case, where they can have little to enthuse over.

I do not state that orthoptic exercises may not be of use, this is still not proven. The question is whether the results are permanent or temporary, and whether they are worth while from the economic standpoint in certain types of cases.

I thank Mr. Lyle for his great profundity in the matter of the "cover" test. In view of the proved presence of full stereoscopic vision in this case, in December, 1941, it should have been appare t to him that the "cover" test was being used to show continued incomitance of the esophoria present.

With regard to Case 2 , it seems to me that $\mathrm{Mr}$. Lyle is rather rash in assuming that because this patient was orthophoric in the horizontal meridian he would make use of this meridian exclusively in all the gyrations of driving a motor cycle, a motor car, and flying an aeroplane. Considerable right hyperphoria $\left(10^{\star}\right)$ was present 
on looking downwards, with esophoria $\left(6^{\Delta}\right)$, yet he experienced no discomfort. It was decided to ask this patient to attend again, and he was seen on September 14,1942, when it was found that he now saw 4 Worth's lights in all meridia, and that there was full fusion on the synoptophore even looking downwards to the extent of $7 \Delta$.

It will be noted that these results differ from those obtained on January 29, 1942, when 4 Worth's lights were only seen in the horizontal meridian. It is obvious, therefore, that this patient is over-coming his hyperphoria, and developing fusion in other meridia than the horizontal.

On questioning him, the patient states that he had been flying aeroplanes for 1 year before his accident. He has not noticed any difference in his handling of aircraft since the accident, and has had nothing untoward, either in taking off or in landing planes.

If this case had been given orthoptic exercises, would he not have been claimed as a successful result of such treatment?

With regard to the correct immediate treatment of fractures of the orbit, our report made it quite clear that we inherited this case 6-7 weeks after the accident.

In conclusion, I venture to suggest that it is certainly possible to dearn something from these "Two cases of orthoptic interest."

Yours faithfully,

\section{TREE.}

- BiRMINGHAM,

September 30, 1942

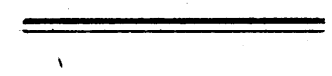

NOTES

\section{Honour}

AMONG recent recipients of honours in the Major H. B. Stallard, who receives the M.B.E.

Middle East we are glad to see the name of Major. H. B. Stallard, who receives the M.B.E.

Sociedade de Oftalmologia de Sao' Paulo

THE following officers have been selected for the session 1942-43. President, W. Belfort Mattos; Vice-President, P. C. de Castro; Secretaries, Silvio de Almeida Toledo and Renato de Toledo; Treasurer, Francisco Amendola; Archivist, Jose M. de Barros. 